\title{
One in Seven Insulin-Treated Patients in Developing Countries Reported Poor Persistence with Insulin Therapy: Real World Evidence from the Cross- Sectional International Diabetes Management Practices Study (IDMPS)
}

Juliana C. N. Chan · Juan José Gagliardino · Hasan Ilkova · Fernando Lavalle • Ambady Ramachandran • Jean Claude Mbanya · Marina Shestakova · Cecile Dessapt-Baradez · Jean-Marc Chantelot •

Pablo Aschner

Received: February 2, 2021 / Accepted: March 30, 2021 / Published online: May 12, 2021

(c) The Author(s) 2021

\section{ABSTRACT}

Introduction: Although poor adherence to insulin is widely recognised, periodic discontinuation of insulin may cause more severe

Supplementary Information The online version contains supplementary material available at https:// doi.org/10.1007/s12325-021-01736-4.

J. C. N. Chan ( $\square)$

Department of Medicine and Therapeutics, Hong Kong Institute of Diabetes and Obesity and Li Ka Shing Institute of Health Sciences, The Chinese University of Hong Kong, The Prince of Wales Hospital, Shatin, Hong Kong SAR, China e-mail: jchan@cuhk.edu.hk

\section{J. J. Gagliardino}

CENEXA, Center of Experimental and Applied Endocrinology (La Plata National University-La Plata National Scientific and Technical Research Council), La Plata, Argentina

\section{H. Ilkova}

Division of Endocrinology Metabolism and Diabetes, Department of Internal Medicine, Cerrahpasa Medical Faculty, Istanbul University, Istanbul, Turkey

F. Lavalle

Facultad de Medicina de la Universidad Autónoma de Nuevo León, Monterrey, Mexico

A. Ramachandran

India Diabetes Research Foundation, Dr.

A. Ramachandran's Diabetes Hospitals, Chennai, India hyperglycaemia than poor adherence. We assessed persistence with insulin therapy in patients with type 1 (T1D) or type 2 diabetes (T2D) in developing countries and the reasons for insulin discontinuation.

Methods: The International Diabetes Management Practices Study collected real-world data from developing countries in seven waves between 2005 and 2017. In Wave 7

\section{J. C. Mbanya}

Biotechnology Center, Doctoral School of Life Sciences, Health and Environment, Faculty of Medicine and Biomedical Sciences, University of Yaounde I, Yaounde, Cameroon

M. Shestakova

Endocrinology Research Center, Moscow, Russia

M. Shestakova

I.M. Sechenov First Moscow State Medical

University, Moscow, Russia

C. Dessapt-Baradez

Sanofi, Reading, UK

J.-M. Chantelot

Sanofi, Paris, France

P. Aschner

Javeriana University School of Medicine, Bogotá, Colombia

P. Aschner

San Ignacio University Hospital, Bogotá, Colombia 
(2016-2017), we asked adult patients with T1D and insulin-treated T2D to report whether they had ever discontinued insulin, the estimated duration of discontinuation and underlying reasons.

Results: Among 8303 patients recruited from 24 countries by 620 physicians, 4596 were insulin-treated (T1D: 2000; T2D: 2596). In patients with T1D, $14.0 \%$ (95\% CI: 12.5-15.6) reported having self-discontinued insulin for a median duration of 1.0 month (IQR: $0.5,3.5$ ). The respective figures in patients with T2D were 13.7\% (12.4-15.1) and 2.0 months (IQR: 1.0, 6.0). The main reasons for discontinuation were impact on social life (T1D: 41.0\%; T2D: 30.5\%), cost of medications and test strips (T1D: $34.4 \%$; T2D: $24.5 \%$ ), fear of hypoglycaemia (T1D: 26.7\%; T2D: $28.0 \%$ ) and lack of support (T1D: 26.4\%; T2D: 25.9\%). Other factors included age $<40$ years, non-university education and short disease duration (T1D: $\leq 1$ year; T2D: $>1-\leq 5$ years). Patients with T1D who did not perform self-monitoring of blood glucose (SMBG) or self-adjust their insulin dosage, and patients with T1D or T2D without glucose meters were less likely to persist with insulin. Nearly $50 \%$ of patients who reported poor persistence had $\mathrm{HbA}_{1 \mathrm{c}}>75 \mathrm{mmol} / \mathrm{mol}(>9 \%)$ and $>50 \%$ of physicians recommended diabetes education programmes to improve treatment persistence.

Conclusion: In developing countries, poor persistence with insulin is common among insulintreated patients, supporting calls for urgent actions to ensure easy access to insulin, tools for SMBG and education.

\section{Graphical Abstract:}

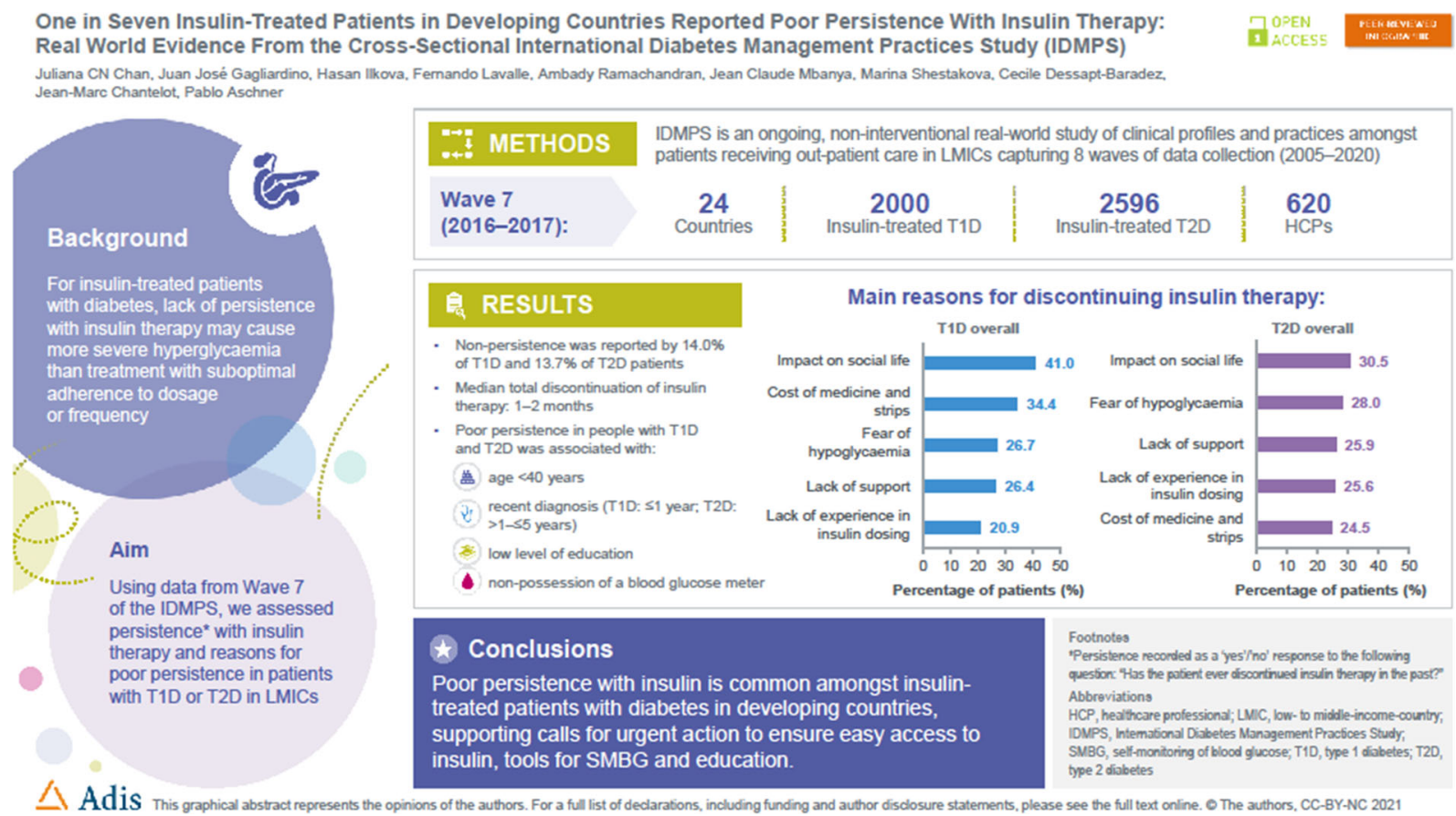


Keywords: Clinical science and Healthcare delivery; Insulin therapy

\section{Key Summary Points}

Why carry out this study?

In developing countries, there are multiple barriers to persistence with insulin therapy, including access, cost and support, but data are limited on the magnitude of non-persistence and underlying reasons for this in insulinrequiring patients in developing countries.

Our study aimed to determine what proportion of patients with type 1 (T1D) or type 2 diabetes (T2D) did not persist with their insulin therapy, and why.

\section{What was learned from the study?}

One in seven insulin-treated patients (T1D: $14.0 \%$ and T2D: $13.7 \%$ ) in developing countries reported nonpersistence with insulin, with an average duration of discontinuation of 1-2 months; fear of hypoglycaemia, impact on social life, cost of medications/ strips and lack of support were the main reasons reported for poor persistence with insulin therapy.

In patients with $\mathrm{T} 1 \mathrm{D}$ or $\mathrm{T} 2 \mathrm{D}$, young age ( $<40$ years), recent diagnosis

T1D: $\leq 1$ year; T2D: $>1-\leq 5$ years), lower levels of education and lack of selfmonitoring of blood glucose (SMBG) tools were associated with poor persistence with insulin therapy.

Reform of diabetes care delivery is needed to close care gaps and improve persistence with insulin therapy, including providing resources, building capacity and implementing policies to ensure easy access to insulin, education and SMBG tools.

\section{care; DIGITAL FEATURES}

This article is published with digital features, including a summary slide and graphical abstract, to facilitate understanding of the article. To view digital features for this article go to https://doi.org/10.6084/m9.figshare.14333630.

\section{INTRODUCTION}

Diabetes affects 463 million people worldwide, $80 \%$ of whom live in developing countries [1] where disease patterns and standards of care practices are largely unknown. While type 1 diabetes (T1D) is characterised by absolute insulin deficiency, often due to autoimmunity, patients with type 2 diabetes (T2D) often have inadequate insulin secretion to control blood glucose. The latter can be influenced by, but are not limited to, genetic, lifestyle and environmental factors $[2,3]$. In both white and nonwhite populations, $10-20 \%$ of adult patients with T2D have significant insulin deficiency due to autoimmune or genetic causes and/or long disease duration, notably those with low body mass index (BMI) and young age at onset of disease [4].

Insulin therapy is essential for survival in patients with T1D, while many patients with T2D eventually require insulin therapy upon failure with oral glucose-lowering drugs (OGLDs) [5]. In closely monitored clinical trial settings, insulin is highly efficacious in helping patients reach their recommended glycaemic goal, often defined as $\mathrm{HbA}_{1 \mathrm{c}}<53 \mathrm{mmol} / \mathrm{mol}$ $(<7.0 \%)$ [6]. However, this is often not achieved in real-world practice in either developed and developing countries.[7-10] Apart from delayed treatment intensification $[9,11]$ and inappropriate insulin regimen selection by physicians (including dose, frequency or insulin type), patients' non-adherence to treatment regimen can lead to poor glycaemic control [12]. To this end, lack of persistence with insulin therapy can result in more severe hyperglycaemia than continuing treatment with suboptimal adherence to dosage or frequency.

In developed countries, common barriers to insulin initiation, titration and adherence 
include fear of hypoglycaemia, weight gain, anxiety, lack of education regarding insulin injection and insufficient communication between physicians and patients [11, 13]. In developing countries, poor access to care, lack of free or subsidised medications, low levels of general education, poor disease awareness and lack of access to diabetes education and selfmanagement programs are additional factors contributing to poor glycaemic control [14]. The extent to which these factors might influence persistence with insulin is largely unknown in developing countries.

The International Diabetes Management Study (IDMPS) is a large observational programme which tracks patient profiles and care patterns across time in developing countries, against a backdrop of increasing knowledge and technologies for improving diabetes care [7, 15-20]. Over 6000 physicians from 49 countries across Africa, the Middle East, South Asia, Latin America, Asia and Eurasia have participated in the study. Data were collected using structured case report forms in a series of 'waves', with each wave recruiting a new cohort of patients. The first wave commenced in 2005 and, to date, seven waves of data have been collected from 81,000 patients. Apart from a standard set of data collected in all waves, each wave also had a focus, such as defining determinants for achieving glycaemic goal (Wave 1) [15], use of healthcare resources (Wave 2) [16], barriers to initiating insulin (Wave 3) [18], hypoglycaemia (Wave 4), symptoms of depression (Wave 5) [20], and self-management (Wave 6). In a recent trend analysis of IDMPS data from Waves $1-7$, despite the increasing number of therapy options and drug delivery systems, there was no improvement in glycaemic control in patients with T2D over time with less than $30 \%$ of insulin-treated patients achieving an $\mathrm{HbA}_{1 \mathrm{c}}$ goal of $<53 \mathrm{mmol} / \mathrm{mol}(<7 \%)$ [7].

To understand the reasons for persistently poor glycaemic control, especially in insulintreated patients, in Wave 7 of the IDMPS (2016-2017), we examined two specific questions: (1) how common was self-discontinuation of insulin in insulin-requiring patients, and (2) what were the underlying reasons for poor persistence with insulin?

\section{METHODS}

\section{Study Design and Participants}

The IDMPS is an ongoing multicentre, crosssectional study with published methodologies [15]. In brief, during a 2-week recruitment period of the IDMPS Wave 7 (2016-2017), participating physicians were asked to enter details of the first 5 patients with T1D and the first 10 patients with T2D who visited their clinics. Participating physicians were selected based on their experience with insulin therapy and could participate in more than one wave of data collection. All patients gave written informed consent. Ethics approval was obtained from institutional review boards in each country and the study was conducted in accordance with the Declaration of Helsinki. Details of the informed consent form, along with information on national coordinators and participating physicians, can be found in the Supplementary Materials. In the current wave, patients were recruited from 24 countries across Africa, the Middle East, South Asia, Latin America, Asia and Eurasia.

\section{Inclusion/Exclusion Criteria}

Adults above the lower legal age limit (countryspecific) diagnosed with T1D or T2D were eligible for inclusion. Exclusion criteria included concomitant participation in another clinical study, participation in a previous wave of IDMPS and current receipt of temporary insulin therapy for other underlying conditions.

\section{Outcome Measures}

The primary outcome of this analysis was the proportion of insulin-treated patients with T1D or T2D who had ever self-discontinued insulin, defined as a positive response to the question "Has the patient ever discontinued insulin therapy in the past?". If the response was 'yes', patients were asked to estimate the duration of insulin discontinuation (in months) from commencement of insulin treatment, although all patients were treated with insulin at the time 
of the survey. No information was recorded on the type of insulin that was omitted or the number of missed injections. Reasons for poor persistence were collected using pre-defined fields and open-ended questions. Physicians were able to record more than one reason for discontinuation of therapy or lack of achievement of glycaemic goals. Other outcome measures included attainment of glycaemic goal $\left[\mathrm{HbA}_{1 \mathrm{c}}<53 \mathrm{mmol} / \mathrm{mol}(<7 \%)\right.$ based on laboratory results and physician-set individualised $\mathrm{HbA}_{1 \mathrm{c}}$ goal (yes/no)]. The latter was not predefined, and the physician was not asked to report these individualised goals. Other data included clinical profiles and access to diabetes education. Physicians were also asked to suggest reasons for poor glycaemic control and strategies to improve persistence with insulin therapy.

\section{Statistical Analysis}

All eligible participants from 24 countries without missing data on glucose-lowering drugs were included. Among the 42 variables included, no imputation was performed for missing data except for birth date (if missing, 15 was imputed) or birth month (if missing, June was imputed). Missing data were not counted in percentages. Descriptive data were reported using mean [standard deviation (SD)], median [interquartile range (IQR)] and counts [percentage (\%)] as appropriate. The primary outcome was expressed with 95\% confidence interval (CI). Patients were analysed separately by diabetes type (T1D or T2D). Patients with T2D were further divided according to use of insulin with or without OGLDs. Patients with T1D or T2D were stratified according to whether or not they were persistent with their insulin therapy. Either Fisher's Exact tests or Chisquared tests were used for group comparisons as appropriate, with $p$ values less than 0.05 (2tailed) being significant.

Sample size was determined on a country basis based on the primary objective of IDMPS, which was to assess the treatment patterns of patients with T2D over time. The sample size was calculated to give an estimate of the proportion of patients with $\mathrm{T} 2 \mathrm{D}$ treated with insulin, assuming that insulin was the leastprescribed therapy for these patients (see Supplementary Methods). Physicians experienced in using insulin were selected randomly after stratification based on speciality. The number of participating physicians recruited was based on the country-specific estimated patient sample size required.

\section{RESULTS}

\section{Baseline Characteristics}

Between 26 January 2016 and 13 October 2016, 8426 patients were recruited by 620 physicians from 24 countries, with almost $40 \%$ of patients being from Africa, mainly the Sub-Saharan region (Table S1). The present analysis included only insulin-treated patients, of whom 2000 patients had T1D and 2596 patients had T2D (Table S2). The latter represented $42 \%$ of 6303 patients with T2D recruited in Wave 7. Patients were predominantly White with approximately $80 \%$ living in urban areas and $30-50 \%$ had received university or higher education (Table 1). Patients with T1D had a mean age of 34 years, mean disease duration of 13.1 years and mean $\mathrm{HbA}_{1 \mathrm{c}}$ of $68 \mathrm{mmol} / \mathrm{mol}$ (8.4\%). Among the insulin-treated patients with T2D, 1936 received OGLDs plus insulin and 660 received insulin only, with mean ages of 57.8 and 59.9 years, respectively. The corresponding mean $\mathrm{HbA}_{1 \mathrm{c}}$ were $70 \mathrm{mmol} / \mathrm{mol}(8.6 \%)$ and $73 \mathrm{mmol} / \mathrm{mol}(8.8 \%)$. Insulin-treated patients with T2D had longer disease duration than those treated with OGLDs plus insulin (Table 1).

\section{Patients with T1D}

Insulin treatment, glycaemic goal attainment and predictive factors of glycaemic control Based on the last recorded $\mathrm{HbA}_{1 \mathrm{c}}$, less than $25 \%$ of patients with T1D achieved the recommended goal of $\mathrm{HbA}_{1 \mathrm{c}}<53 \mathrm{mmol} / \mathrm{mol}$ $(<7 \%)[6]$ and $50 \%$ had an $\mathrm{HbA}_{1 \mathrm{c}}>64 \mathrm{mmol} / \mathrm{mol}$ (>8\%). Approximately $28 \%$ of patients with T1D achieved their 
Table 1 Baseline characteristics and patterns of insulin usage among insulin-treated patients participating in Wave 7 of the IDMPS (2016-2017)

\begin{tabular}{|c|c|c|c|}
\hline \multirow{2}{*}{$\begin{array}{l}\text { Age, yearsCharacteristics } \\
\text { Therapy type }\end{array}$} & \multirow[t]{2}{*}{ T1D $(n=2000)$} & \multicolumn{2}{|l|}{ T2D $(n=2596)$} \\
\hline & & $\begin{array}{l}\text { OGLD plus insulin } \\
n=1936\end{array}$ & $\begin{array}{l}\text { Insulin only } \\
n=660\end{array}$ \\
\hline Age, years & $34.0(12.3)$ & $57.8(10.6)$ & $59.9(11.5)$ \\
\hline Female sex, $n(\%)$ & $1024(51.2)$ & $1094(56.5)$ & $354(53.6)$ \\
\hline Weight, kg & $69.9(14.8)$ & $83.2(16.9)$ & $78.8(16.4)$ \\
\hline Body mass index, $\mathrm{kg} / \mathrm{m}^{2}$ & $23.2(5.0)$ & $30.2(5.8)$ & $28.2(6.0)$ \\
\hline Time since diagnosis, years & $13.1(9.9)$ & $12.8(7.5)$ & $13.5(8.8)$ \\
\hline \multicolumn{4}{|l|}{ Ethnicity, $n$ (\%) } \\
\hline White & $1005(50.3)$ & $720(37.2)$ & $308(46.7)$ \\
\hline South Asian & $137(6.9)$ & $365(18.9)$ & $81(12.3 \%)$ \\
\hline Black & $296(14.8)$ & $263(13.6)$ & $130(19.7)$ \\
\hline East Asian, Arab, Persian & $544(27.2)$ & $519(26.8)$ & $111(16.8)$ \\
\hline Other & $18(0.9)$ & $69(3.6)$ & $30(4.6)$ \\
\hline \multicolumn{4}{|l|}{ Living area, $n(\%)$} \\
\hline Urban area & $1676(83.8)$ & $1531(79.1)$ & $520(78.8)$ \\
\hline Rural area & $202(10.1)$ & $225(11.6)$ & $98(14.8)$ \\
\hline Suburban area & $122(6.1)$ & $180(9.3)$ & $42(6.4)$ \\
\hline \multicolumn{4}{|l|}{ Education level, $n(\%)$} \\
\hline Illiterate & $43(2.2)$ & $148(7.6)$ & $66(10.0)$ \\
\hline Primary & $168(8.4)$ & $347(17.9)$ & $105(15.9)$ \\
\hline Secondary & $776(38.8)$ & $775(40.1)$ & $274(41.5)$ \\
\hline University/higher education & $1012(50.6)$ & $665(34.4)$ & $215(32.6)$ \\
\hline $\begin{array}{l}\text { Participation in structured diabetes education } \\
\text { programme, } n(\%)\end{array}$ & $943(61.8)$ & $839(55.6)$ & $275(52.8)$ \\
\hline $\mathbf{H b A}_{1 \mathrm{c}}, \%$ & $8.4(1.9)$ & $8.6(1.8)$ & $8.8(2.3)$ \\
\hline \multicolumn{4}{|l|}{ Categories of $\mathrm{HbA}_{1 \mathrm{c}}$ level, $n(\%)$} \\
\hline$<53 \mathrm{mmol} / \mathrm{mol}(<7 \%)$ & $403(21.8)$ & $253(14.2)$ & $120(20.7)$ \\
\hline$\geq 53-\leq 64 \mathrm{mmol} / \mathrm{mol}(\geq 7-\leq 8 \%)$ & $518(28.0)$ & $560(31.4)$ & $158(27.3)$ \\
\hline$>64 \mathrm{mmol} / \mathrm{mol}(>8 \%)$ & $928(50.2)$ & $973(54.5)$ & $301(52.0)$ \\
\hline $\begin{array}{l}\text { Attained glycaemic goals as defined by attending } \\
\text { physician, } n \text { (\%) }\end{array}$ & $553(28.3)$ & $518(27.6)$ & $199(31.3)$ \\
\hline Duration of insulin treatment, years & $12.6(9.9)$ & $4.2(4.3)$ & $6.1(5.8)$ \\
\hline
\end{tabular}


Table 1 continued

\begin{tabular}{llll}
\hline Age, yearsCharacteristics & T1D $(\boldsymbol{n}=\mathbf{2 0 0 0})$ & T2D $(\boldsymbol{n}=\mathbf{2 5 9 6})$ & \\
\hline Therapy type & & $\begin{array}{l}\text { OGLD plus insulin } \\
\boldsymbol{n}=\mathbf{1 9 3 6}\end{array}$ & $\begin{array}{l}\text { Insulin only } \\
\boldsymbol{n}=\mathbf{6 6 0}\end{array}$ \\
\hline $\begin{array}{l}\text { Type of insulin regimen, } \boldsymbol{n}(\%) \\
\text { Basal alone }\end{array}$ & $62(3.1)$ & $786(40.6)$ & $59(9.0)$ \\
Premixed alone & $388(19.4)$ & $651(33.6)$ & $280(42.5)$ \\
Basal plus prandial & $1332(66.7)$ & $438(22.6)$ & $277(42.0)$ \\
Mean daily insulin dose, IU/kg & & & $0.41(0.22)$ \\
Basal alone & $0.45(0.19)$ & $0.32(0.19)$ & $0.54(0.25)$ \\
Premixed alone & $0.66(0.29)$ & $0.57(0.30)$ & $0.78(0.34)$ \\
Basal plus prandial & $0.82(0.33)$ & $0.76(0.33)$ &
\end{tabular}

Data shown are mean (SD) unless stated otherwise. Data for patients with T2D are available split by therapy subgroup only $O G L D$ oral glucose lowering drugs; SD standard deviation; T1D type 1 diabetes; T2D type 2 diabetes

physician-set individualised goal (Table 1). More than $60 \%$ of patients with T1D received basal plus prandial insulin therapy. The mean daily insulin doses for any insulin regimen was $0.45-0.82 \mathrm{IU} / \mathrm{kg}$ (Table 1 ). The main reasons for not attaining glycaemic goal included fear of hypoglycaemia (40.8\%), lack of insulin titration $(38.9 \%)$, day-to-day fluctuation of blood glucose $(34.5 \%)$, cost of medications/strips (30.2\%) and non-adherence to insulin therapy (11.5\%) (Fig. 1a).

\section{Persistence with insulin therapy}

Overall, 273 [14.0\% (95\% CI: 12.5-15.6)] patients with T1D reported having discontinued their insulin therapy in the past. The estimated median total duration of discontinuation was 1.0 month (IQR: $0.5,3.5$ ). Impact on social life $(41.0 \%)$, cost of medications and test strips (34.4\%), fear of hypoglycaemia (26.7\%), lack of support $(26.4 \%)$ and insufficient experience in insulin dosing (20.9\%) were the most frequent reasons for poor persistence (Fig. 1b). Openended questions yielded additional responses including psychological factors (e.g. depression, lack of motivation, fear of injections) (Table S3).
Clinical profiles associated with poor persistence with insulin and physicians' recommendations to improve persistence Patients with T1D were more likely to have discontinued insulin if they were young $(<40$ years) and newly diagnosed ( $<1$ year), did not receive university education, had diabetesrelated complications or did not perform diabetes self-management (Table 2). Among patients with poor persistence with insulin, $44.7 \%$ had health insurance compared with $64.0 \%$ of those who persisted with insulin. Among patients with $\mathrm{HbA}_{1 \mathrm{c}}>75 \mathrm{mmol} / \mathrm{mol}$ (>9\%), nearly $50 \%$ reported having discontinued insulin in the past (Table 3). Approximately $62 \%$ of physicians recommended diabetes education as a strategy for improving persistence with insulin treatment in patients with T1D. Other recommendations included financial support for medications $(51.6 \%)$ and counselling by a diabetes nurse (33.4\%) (Fig. 1c).

\section{Patients with T2D}

Insulin treatment, glycaemic goal attainment and predictive factors of glycaemic control Based on the last recorded $\mathrm{HbA}_{1 \mathrm{c}}$, approximately $20 \%$ of insulin-treated patients with T2D attained $\mathrm{HbA}_{1 \mathrm{c}}<53 \mathrm{mmol} / \mathrm{mol} \quad(<7 \%)$, and 
a

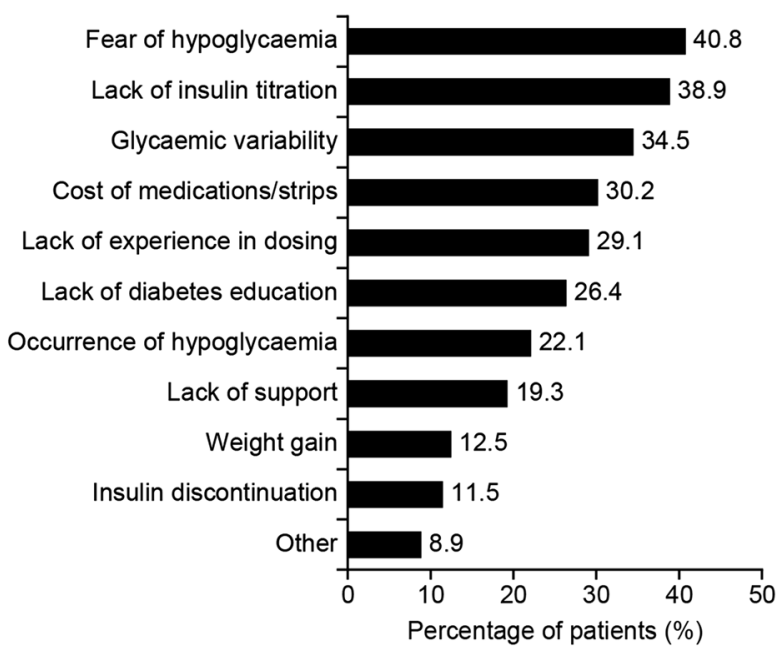

b

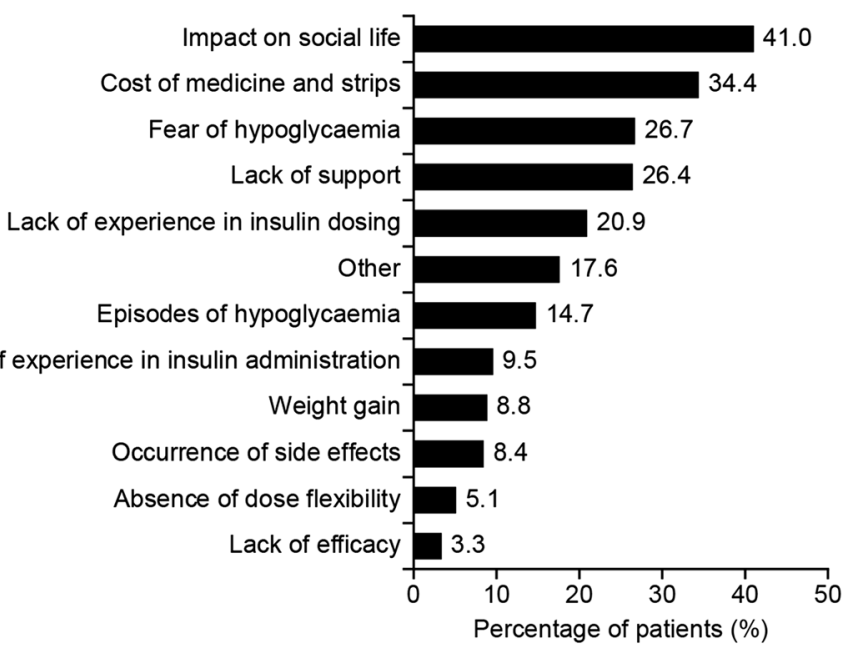

C

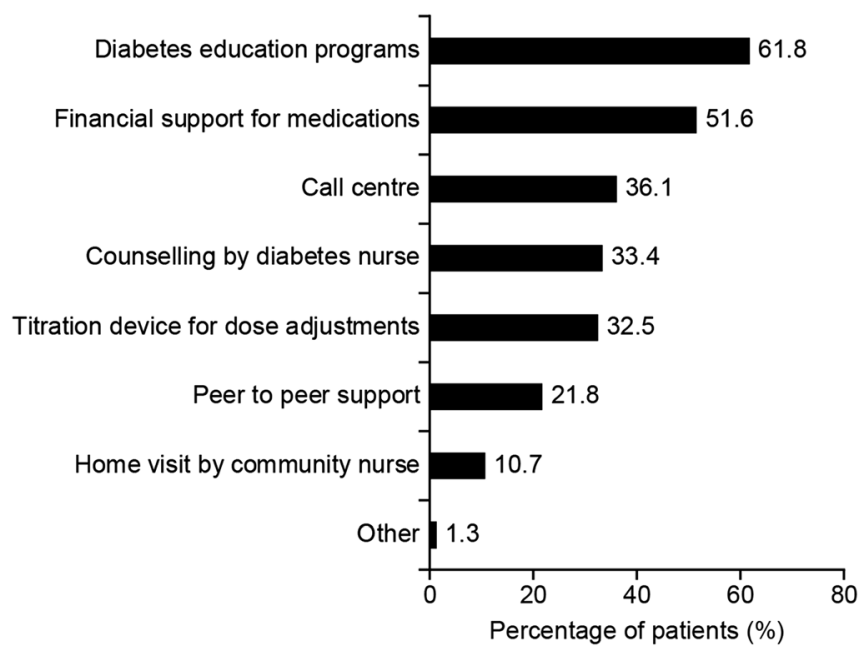

Fig. 1 a Reasons for non-achievement of glycaemic goal; b reasons for poor persistence with insulin therapy and c physician recommendations to improve persistence with insulin therapy in patients with T1D. Physicians were able to record more than one reason for lack of achievement of glycaemic goals 
Table 2 Patient profiles according to status of insulin adherence

\begin{tabular}{lc}
\hline$n(\%)$ & $\begin{array}{l}\text { T1D }(n=200 \\
\text { Poor persis } \\
\text { with insulin } \\
(\boldsymbol{n}=273)\end{array}$ \\
\hline Age by categories, years, $\boldsymbol{n}(\%)$ \\
$\leq 40$ & $217(79.5)$ \\
$>40-\leq 65$ & $52(19.0)$ \\
$>65-\leq 85$ & $4(1.5)$ \\
$>85$ & $0(0.0)$
\end{tabular}

Sex, female, $\boldsymbol{n}(\%) \quad 132(48.4)$

$\begin{array}{llll}\begin{array}{l}\text { Persistent with } \\ \text { insulin } \\ (\boldsymbol{n}=\mathbf{1 6 8 2})\end{array} & \boldsymbol{p} \text { values } & \begin{array}{l}\text { T2D }^{\mathbf{b}}(\boldsymbol{n}=25 \\ \text { Poor persist } \\ \text { with insulin } \\ (\boldsymbol{n}=347)\end{array} \\ 1235(73.4) & 0.034 & 34(9.8) \\ 417(24.8) & 0.039 & 241(69.5) \\ 30(1.8) & >0.99^{\mathrm{c}} & 71(20.5) \\ 0(0.0) & - & 1(0.3)\end{array}$

$868(51.6)$

$$
0.32 \quad 191(55.0)
$$

Persistent with $p$ values insulin

$(n=2190)$

Time since diabetes diagnosis categorised by years, $n$ (\%)

$\begin{array}{llllr}\leq 1 & 34(12.5) & 118(7.0) & 0.002 & 9(2.6) \\ >1-\leq 5 & 54(19.8) & 286(17.0) & 0.26 & 65(18.7) \\ >5-\leq 10 & 71(26.0) & 377(22.4) & 0.19 & 97(28.0) \\ >10-\leq 20 & 73(26.7) & 574(34.1) & 0.016 & 139(40.1) \\ >20 & 41(15.0) & 326(19.4) & 0.086 & 37(10.7)\end{array}$

Education level, $n$ (\%)

$\begin{array}{lr}\text { Illiterate } & 9(3.3) \\ \text { Primary } & 37(13.6) \\ \text { Secondary } & 136(50.0) \\ \text { University/higher } & 90(33.1) \\ \quad \text { education } & \end{array}$

$\begin{array}{clr}30(1.8) & 0.095 & 43(12.4) \\ 127(7.6) & <0.001 & 85(24.5) \\ 627(37.3) & <0.001 & 124(35.7) \\ 898(53.4) & <0.001 & 95(27.4)\end{array}$

$161(7.4)$

0.001

$353(16.1)<0.001$

$906(41.4) \quad 0.046$

Employment status, $n$ (\%)

\begin{tabular}{|c|c|c|c|c|c|c|}
\hline Full time & $105(38.5)$ & $946(56.2)$ & $<0.001$ & $120(34.6)$ & $692(31.6)$ & 0.27 \\
\hline Part time & $40(14.7)$ & $145(8.6)$ & 0.002 & $13(3.7)$ & $106(4.8)$ & 0.37 \\
\hline Not employed & $84(30.8)$ & $388(23.1)$ & 0.006 & $52(15.0)$ & $272(12.4)$ & 0.18 \\
\hline $\begin{array}{l}\text { Full time } \\
\text { homemaker }\end{array}$ & $36(13.2)$ & $154(9.2)$ & 0.037 & $92(26.5)$ & $440(20.1)$ & 0.006 \\
\hline Retired & $8(2.9)$ & $49(2.9)$ & 0.99 & $70(20.2)$ & $680(31.1)$ & $<0.001$ \\
\hline \multicolumn{7}{|c|}{ Diabetes-related complications, $n(\%)$} \\
\hline $\begin{array}{l}\text { Any diabetes-related } \\
\text { complication }\end{array}$ & $144(56.5)$ & $808(49.3)$ & 0.032 & $236(69.6)$ & $1472(68.0)$ & 0.55 \\
\hline $\begin{array}{l}\geq 1 \text { microvascular } \\
\text { complication }\end{array}$ & $130(51.0)$ & $777(47.4)$ & 0.28 & $223(65.8)$ & $1373(63.4)$ & 0.40 \\
\hline
\end{tabular}


Table 2 continued

\begin{tabular}{|c|c|c|c|c|c|c|}
\hline \multirow[t]{2}{*}{$n(\%)$} & \multicolumn{3}{|l|}{ T1D $(n=2000)^{a}$} & \multicolumn{3}{|l|}{$\mathrm{T}^{2} \mathrm{D}^{\mathrm{b}}(n=2596)^{\mathrm{a}}$} \\
\hline & $\begin{array}{l}\text { Poor persistence } \\
\text { with insulin } \\
(n=273)\end{array}$ & $\begin{array}{l}\text { Persistent with } \\
\text { insulin } \\
(n=1682)\end{array}$ & $p$ values & $\begin{array}{l}\text { Poor persistence } \\
\text { with insulin } \\
(n=347)\end{array}$ & $\begin{array}{l}\text { Persistent with } \\
\text { insulin } \\
(n=2190)\end{array}$ & $p$ values \\
\hline $\begin{array}{l}\geq 1 \text { macrovascular } \\
\text { complication }\end{array}$ & $15(5.9)$ & $99(6.0)$ & 0.92 & $78(23.0)$ & $535(24.7)$ & 0.50 \\
\hline \multicolumn{7}{|c|}{ Self-monitoring and self-management practices, $n(\%)$} \\
\hline $\begin{array}{l}\text { Possession of } \\
\text { glucose meter }\end{array}$ & $209(77.4)$ & $1533(91.3)$ & $<0.001$ & $253(73.1)$ & $1811(83.3)$ & $<0.001$ \\
\hline $\begin{array}{l}\text { Self-monitoring of } \\
\text { blood glucose }\end{array}$ & $191(91.8)$ & $1493(97.8)$ & $<0.001$ & $235(93.3)$ & $1713(95.3)$ & 0.17 \\
\hline $\begin{array}{l}\text { Self-adjusted insulin } \\
\text { dose }\end{array}$ & $171(64.3)$ & $1229(74.7)$ & $<0.001$ & $135(40.8)$ & $999(46.3)$ & 0.061 \\
\hline
\end{tabular}

Data shown are $n$ (\%); $p$ values denote differences between proportion of participants who were adherent versus those who were non-adherent to insulin therapy

$O G L D$ oral glucose-lowering drug; TID type 1 diabetes; T2D type 2 diabetes

a Data on adherence status were missing for 45 patients with T1D and 59 patients with T2D (data not shown)

b Results for patients with T2D are shown for the overall insulin-treated population (insulin only and insulin plus OGLD groups combined

c Fisher's Exact test was used; otherwise, Chi-squared test was used

more than $50 \%$ had $\mathrm{HbA}_{1 \mathrm{c}}>64 \mathrm{mmol} / \mathrm{mol}$ (>8\%) (Table 1). Approximately $30 \%$ of insulintreated patients with T2D attained their individualised physician-set goals. The main reasons for not attaining individualised glycaemic goals included lack of insulin titration by physicians (39.1\%), insufficient experience of self-adjustment of insulin dosing (35.9\%), lack of diabetes education (35.0\%) and poor persistence with insulin (9.9\%). Similar patterns were observed in patients treated with insulin only or insulin plus OGLDs (Fig. 2a, d). In the latter group, basal insulin only was the most prescribed regimen (40.6\%). Among those receiving insulin only, premixed insulin was the most prescribed regimen (42.5\%). The mean daily insulin doses ranged between $0.32-0.78 \mathrm{IU} / \mathrm{kg}$ across different insulin regimens (Table 1 ).

\section{Persistence with insulin therapy}

Overall, $13.7 \%$ (95\% CI: $12.4-15.1$ ) of patients with T2D [OGLD plus insulin: $n=261,13.8 \%$
(95\% CI: $12.3-15.4$ ); insulin only: $n=86,13.4 \%$ (95\% CI: 10.9-16.3)] reported having discontinued their insulin therapy in the past. The estimated median total duration of discontinuation was 2.0 months (IQR: 1.0, 6.0). Impact on social life $(30.5 \%)$, fear of hypoglycaemia (28.0\%), lack of support (25.9\%), lack of experience in insulin dosing $(25.6 \%)$ and cost of medications and test strips (24.5\%) were the main reasons for poor persistence (Fig. 2b, e). Answers to open-ended questions yielded additional responses including shortage of insulin supply, fear of injections and Ramadan (Table S3).

\section{Clinical profiles associated with poor persistence with insulin and physicians' recommendations to improve persistence} Insulin-treated patients with T2D were more likely to have discontinued insulin in the past if they were $<40$ years old, diagnosed within 1-5 years, did not have a secondary school 
Table 3 Mean $\mathrm{HbA}_{1 \mathrm{c}}$ and glycaemic control according to status of insulin persistence

\begin{tabular}{|c|c|c|c|c|}
\hline & \multicolumn{2}{|l|}{$\operatorname{T1D}(n=2000)^{\mathrm{a}}$} & \multicolumn{2}{|l|}{$\mathrm{T}^{2} \mathrm{D}^{\mathrm{b}}(n=2596)^{\mathrm{a}}$} \\
\hline & $\begin{array}{l}\text { Poor persistence with } \\
\text { insulin } \\
(n=273)\end{array}$ & $\begin{array}{l}\text { Persistent with } \\
\text { insulin } \\
(n=1682)\end{array}$ & $\begin{array}{l}\text { Poor persistence with } \\
\text { insulin } \\
(n=347)\end{array}$ & $\begin{array}{l}\text { Persistent with } \\
\text { insulin } \\
(n=2190)\end{array}$ \\
\hline \multicolumn{5}{|c|}{ Value of last $\mathrm{HbA}_{1 \mathrm{c}}$ measurement, mean (SD) } \\
\hline$n$ & 230 & 1582 & 317 & 1998 \\
\hline $\mathrm{mmol} / \mathrm{mol}$ & $76.7(23.5)$ & $66.9(19.8)$ & $78.5(24.6)$ & $69.8(20.5)$ \\
\hline$\%$ & $9.17(2.15)$ & $8.27(1.81)$ & $9.33(2.25)$ & $8.54(1.88)$ \\
\hline \multicolumn{5}{|l|}{ Glycaemic control, $n$ (\%) } \\
\hline $\begin{array}{l}\mathrm{HbA}_{1 \mathrm{c}} \\
<53 \mathrm{mmol} / \mathrm{mol}(<7 \%)\end{array}$ & $34(14.8)$ & $366(23.1)$ & $37(11.7)$ & $330(16.5)$ \\
\hline $\begin{array}{l}\mathrm{HbA}_{1 \mathrm{c}} \\
53-\leq 64 \mathrm{mmol} / \mathrm{mol} \\
\quad(7-\leq 8 \%)\end{array}$ & $44(19.1)$ & $464(29.3)$ & $67(21.1)$ & $642(32.1)$ \\
\hline $\begin{array}{l}\mathrm{HbA}_{1 \mathrm{c}} \\
64-\leq 75 \mathrm{mmol} / \mathrm{mol} \\
(8-\leq 9 \%)\end{array}$ & $46(20.0)$ & $331(20.9)$ & $66(20.8)$ & $401(20.1)$ \\
\hline $\begin{array}{l}\mathrm{HbA}_{1 \mathrm{c}} \\
>75 \mathrm{mmol} / \mathrm{mol}(>9 \%)\end{array}$ & $106(46.1)$ & $421(26.6)$ & $147(46.4)$ & $625(31.3)$ \\
\hline
\end{tabular}

OGLD oral glucose lowering drugs; SD standard deviation; T1D type 1 diabetes; T2D type 2 diabetes

${ }^{a}$ Data on adherence status were missing for 45 patients with T1D and 59 patients with T2D (data not shown). ${ }^{b}$ Results for patients with T2D are shown for the overall insulin-treated population (insulin only and insulin plus OGLD groups combined)

education, were full-time housekeepers or did not possess a glucose meter (Table 2). Nearly $50 \%$ of patients who had discontinued insulin in the past had $\mathrm{HbA}_{1 \mathrm{c}}>75 \mathrm{mmol} / \mathrm{mol}(>9 \%)$ (Table 3).

Diabetes education was recommended by $54.9 \%$ of physicians for improving persistence with insulin therapy. Other recommendations included counselling by a diabetes nurse (47.6\%), financial support for medications (43.2\%) and a titration device for dose adjustments (31.8\%) (Fig. 2c). Similar recommendations were observed for patients treated with OGLD plus insulin or insulin alone (Fig. 2f).

\section{DISCUSSION}

Apart from treating acute hyperglycaemia, insulin is often initiated as a long-term therapy due to poor glycaemic control and/or a tendency to develop ketosis. In these insulin-requiring patients, discontinuation of insulin can lead to severe hyperglycaemia or metabolic decompensation. Many studies have assessed patient adherence (generally defined as continuing therapy, albeit not in accordance to the prescribed regimen) to glucose-lowering drugs, yet there are few studies that have examined persistence (generally defined as exposure to 
a

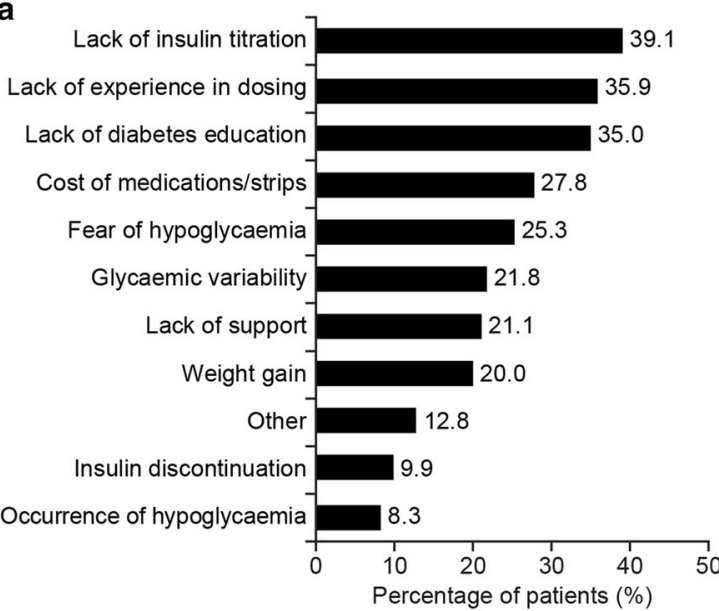

b

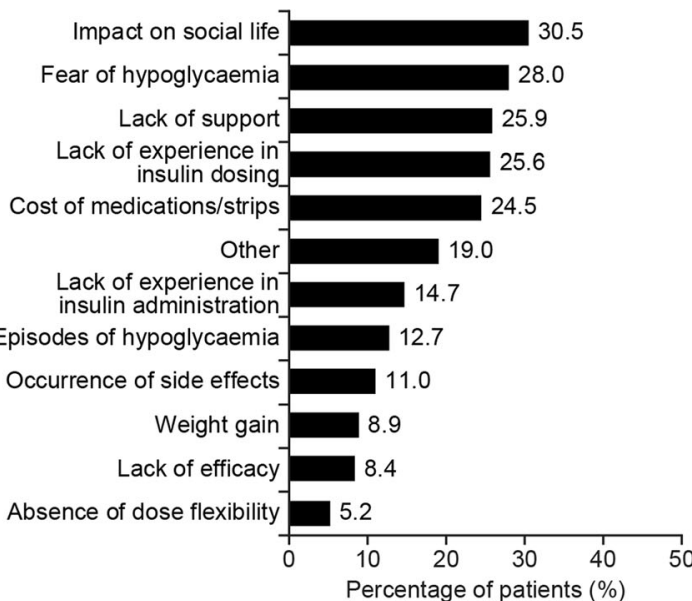

c

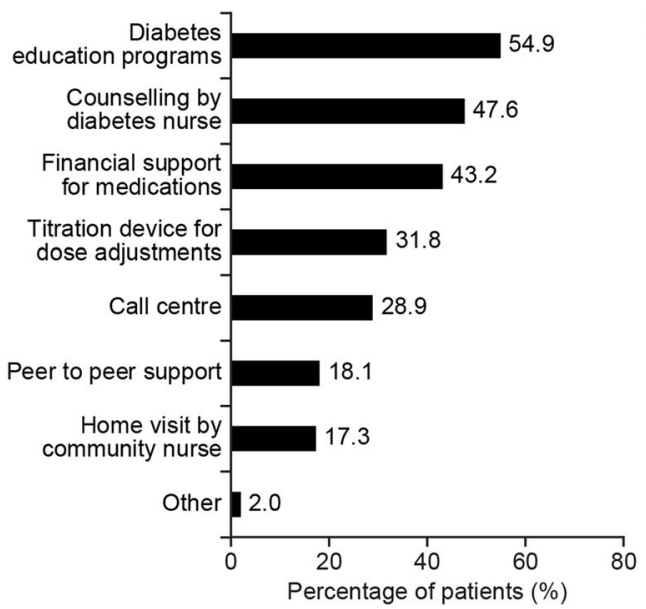

Fig. 2 a, d Reasons for non-achievement of glycaemic goal; b, e reasons for poor persistence with insulin therapy and $\mathbf{c}$, f Physician recommendations to improve persistence with insulin therapy in patients with T2D. Physicians were

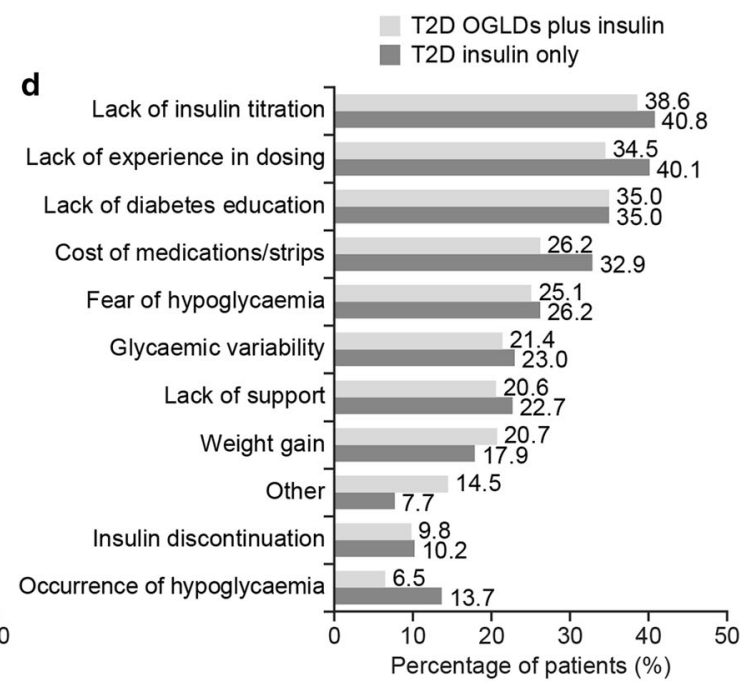

e

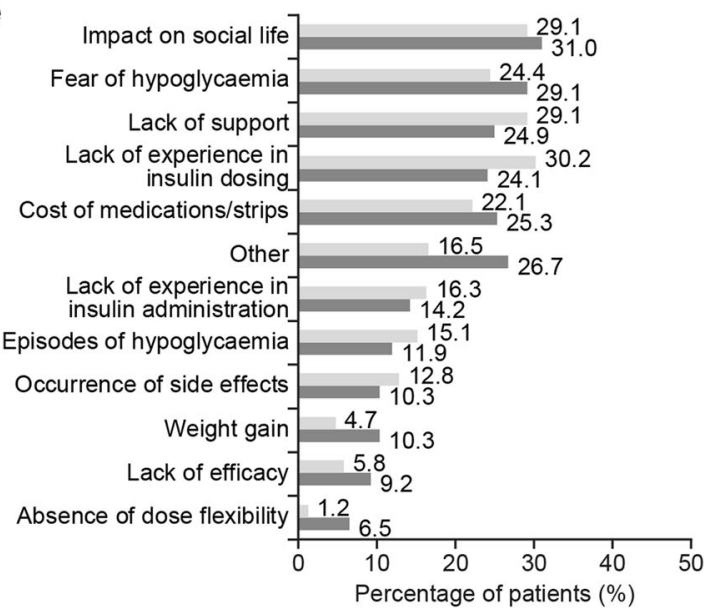

f

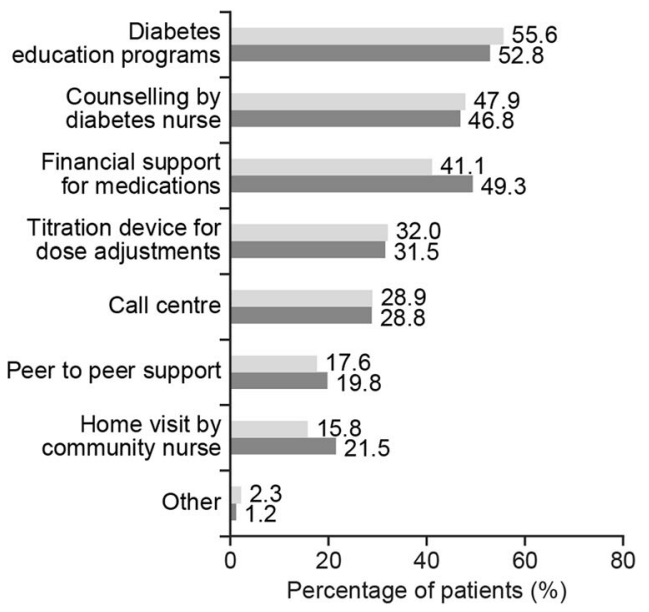

allowed to record more than one reason for patients' discontinuation of therapy. OGLD oral glucose-lowering drugs; $T 2 D$ type 2 diabetes 
treatment for a period of time) with insulin treatment [21]. Given its vital role in reducing blood glucose, poor persistence with insulin therapy could lead to more severe hyperglycaemia compared with non-adherence.

In this analysis, we focussed on poor persistence rather than non-adherence. Using realworld evidence, we revealed for the first time that 1 in 7 patients with T1D or insulin-treated patients with T2D from developing countries reported having discontinued their insulin in the past for an average duration of 1-2 months since commencement of treatment. This poor persistence might contribute to the poor glycaemic control in these patients with almost half of them having an $\mathrm{HbA}_{1 \mathrm{c}}>75 \mathrm{mmol} / \mathrm{mol}$ (>9\%).

Based on pre-specified questions, impact on social life, cost of medications and test strips, fear of hypoglycaemia, lack of support and experience in insulin dosing were common reasons for not persisting with insulin in patients with both T1D and T2D. In patients with T1D, young age ( $<40$ years), recent diagnosis ( $\leq 1$ year), non-university education and insufficient self-management [self-monitoring of blood glucose (SMBG) and self-adjustment of insulin dosage] were additional reasons. In patients with T2D, young age ( $<40$ years), short disease duration ( $>1-\leq 5$ years), non-secondary school education and not possessing a glucose meter were associated with poor persistence with insulin treatment. Although these crosssectional data cannot infer causality, these findings agree with previous reports regarding the importance of both general and diabetesrelated education in influencing self-management skills [17]. The latter is essential for effective use of insulin including SMBG and dose titration in order to attain glycaemic goals.

The lack of diabetes symptoms and demanding nature of self-care mean that many patients may not be aware of the need to persist with insulin, and thus not be motivated to do so. In the present analysis, patients with T1D who discontinued insulin were twofold more likely to be newly diagnosed (within 1 year) than those who persisted with insulin $(12 \%$ vs. $7 \%)$. In patients with newly diagnosed T1D, transient recovery of beta cell function after reversal of acute glucotoxicity by insulin therapy might be followed by a 'honeymoon period' with transient dose reduction or even discontinuation [22]. That said, in the Diabetes Attitudes Wishes and Needs (DAWN) study, 85.2\% of newly diagnosed patients with T1D or T2D reported high levels of diabetes-related distress which was associated with poor adherence [23] and possibly persistence. Other reasons for poor persistence, identified through free-text responses, included emotional distress, lack of insulin supply, high costs of medications and test strips and Ramadan.

In this study, insulin cost was reported as a barrier to persistence. Various researchers have reported associations of poor adherence to insulin with poor glycaemic control, high Charlson Comorbidity Index scores, increased hospitalisation rates (and related costs) and diabetic ketoacidosis [24-27]. Additionally, long-term poor glycaemic control can lead to multiple morbidities [28, 29]. In our previous analysis of IDMPS data, we have also reported independent associations of poor glycaemic control with hospitalisations and absenteeism in patients with T2D [19]. Taken together, it is reasonable to infer that poor persistence would also lead to poor clinical outcomes.

Defining the size of the problem and identifying reasons for poor persistence with insulin therapy is the first step towards formulating solutions. In insulin-naïve patients, good communication skills, empathy and demonstration of injection technique by healthcare providers were rated by patients as being most useful during insulin initiation [30]. Once insulin was initiated, factors such as fear of hypoglycaemia, impact on social life, perceived burden of complex treatment regimens, weight gain and insufficient ongoing support (e.g. insulin titration, meal adjustment, sick day management, interpretation of blood glucose levels) became more important $[11,18,23]$. Overcoming these barriers requires sufficient time to empower and engage patients, which could be more effectively achieved using a team approach rather than sole reliance on physicians to provide education [31].

Previous results from the IDMPS have indicated close associations of glycaemic control 
with possession of blood glucose monitoring devices, SMBG and access to diabetes education $[8,17,32]$. In this analysis, patients with T1D who performed SMBG or self-adjusted insulin dosage and patients with T2D who owned a glucose meter were less likely to have discontinued their insulin therapy in the past. These findings support the critical importance of having access to insulin, tools for SMBG and professional education to help patients selfmanage their insulin therapy.

Motivating behavioural changes is a key component of diabetes management. In this study, patients with T1D or T2D with high levels of education and full-time employment were less likely to have discontinued their insulin therapy in the past. In previous IDMPS waves, we have reported the independent and positive association of high levels of education and access to diabetes education with SMBG, self-titration of insulin and glycaemic control in both patients with T1D or T2D [17]. In Saudi Arabia and Cameroon, patient literacy was closely associated with adherence to therapies $[33,34]$. Low education level and poverty have been associated with increased incidence of allcause and cardiovascular mortality in patients with diabetes after adjusting for confounders $[35,36]$. Taken together, these observations emphasised the socio-biomedical nature of diabetes that requires societal and individualised approaches to optimise care and reduce disease burden [37].

In the present analysis, most physicians recommended provision of diabetes education programmes to improve treatment persistence and glycaemic control. Previous meta-analyses have shown that extended contact time with physicians [38], team-based management, using non-physicians or technology to promote physician-patient communication and providing diabetes education and self-management programmes were effective strategies in reducing $\mathrm{HbA}_{1 \mathrm{c}}$, blood pressure and low-density lipoprotein cholesterol (LDL-C) [39]. These effect sizes were most evident in developing countries where chronic care delivery may be less integrated [39]. Similar results were observed in a study involving 468 patients with T2D attending primary care clinics in Argentina
[40]. Taken together, system change and institutional support are needed to build capacity in order to assess risk, empower patients, intervene early and improve outcomes [31].

In this analysis, cost of medications and test strips were major reasons for poor persistence with insulin, particularly in patients with T1D. Additionally, patients with T1D were more likely to have discontinued insulin in the past if they were not in full-time employment. While data on persistence are lacking in both developing and developed countries, researchers have reported the financial burden of medication costs as a major barrier to adhering to longterm treatment in patients with T2D [34, 41]. Furthermore, in developing countries, medication costs can take up a huge part of the family income for those without medical coverage [14]. The World Health Organization has recommended all governments to include insulin as an 'essential medication' along with other medications for lowering blood pressure, blood glucose and cholesterol as the first step towards improvement [42]. However, without adequate education and tools for SMBG, insulin treatment cannot be administered safely and effectively. There are now many technologies including insulin analogues with a low risk of hypoglycaemia, insulin delivery methods such as injection pens or insulin pumps and continuous glucose monitoring systems, which can improve self-management of insulin therapy. However, reimbursement policies and healthcare systems need to be aligned to make these technologies and education programmes more accessible and affordable [37].

There are limitations in our present analysis. Despite the large sample size with diverse populations and settings, the cross-sectional nature of this study cannot infer causality. Additionally, the small sample size available within the subgroup analyses mean that the clinical characteristics associated with poor persistence with insulin should be interpreted with caution. The lack of common definitions and tools to measure treatment 'adherence' and 'persistence' $[43,44]$ along with patient recall bias/errors may introduce uncertainty. In this survey, all patients were insulin-treated at the time of enrolment, and the physicians asked them to 
recall whether they had ever 'discontinued insulin', recorded as 'yes'/'no'. Due to the pragmatic design and variabilities in terms of insulin regimen, we did not seek details of the pattern of discontinuation. The heterogeneity in socioeconomic development, healthcare providing and financing systems, types of clinic practices, attributes of physicians and patients together with small sample size within each country do not permit more detailed countrylevel analyses. Despite these limitations, the narrow confidence intervals of our estimates of poor persistence together with the patient-reported experiences and poor glycaemic control associated with poor persistence support our conclusions.

\section{CONCLUSIONS}

Poor persistence and self-discontinuation of insulin is a major challenge in diabetes management. These results from developing countries add to the global knowledge regarding these unmet needs. Apart from patient-level barriers such as impact on social life, fear of hypoglycaemia and weight gain, systemic factors such as access to structured education programs with ongoing support as well as affordability of medications/test strips are important barriers to persistence with insulin treatment. These care gaps require alignment of payors, providers, and industry to improve the practice environment, pricing strategies and community support in order to close these care gaps.

\section{ACKNOWLEDGEMENTS}

The authors thank all physicians and patients who participated in the study.

Funding. This study was funded by Sanofi (Paris, France). The sponsor was supported by the steering committee regarding study design, registry structure, protocol amendments, research questions, analyses and publications. Publication fees (including the journal's Rapid Service and Open Access fees) were also funded by Sanofi.
Medical Writing, Editorial and Other Assistance. Coordination of the development of this manuscript and assistance with the revision was provided by Helena Andersson, $\mathrm{PhD}$, at Sanofi. The authors acknowledged medical writing and editorial assistance provided by Hanna Mourad-Agha, PhD, and Hannah Brown, PhD, of Fishawack Communications Ltd, part of Fishawack Health, whose service was funded by Sanofi.

Authorship. All named authors meet the International Committee of Medical Journal Editors (ICMJE) criteria for authorship for this article, take responsibility for the integrity of the work as a whole, and have given their approval for this version to be published.

Authors' Contributions. JCNC wrote the first draft with editorial support from Fishawack Communications Ltd. All authors (JCNC, JJG, HI, FL, AR, JCM, MS, CDB, JMC and PA) made substantial contributions to the acquisition, analysis or interpretation of data for this work and revised the work critically for important intellectual content.

Disclosures. Juliana CN Chan has received research grants and/or honoraria for consultancy or giving lectures from AstraZeneca, Bayer, Boehringer Ingelheim, Eli Lilly, Merck Serono, Merck Sharp \& Dohme, Novartis, Pfizer and Sanofi. Jean-Marc Chantelot and Cecile Dessapt-Baradez are employees of and shareholders in Sanofi. Fernando Lavalle has received research grants and/or honoraria for consultancy or lecture fees from AstraZeneca, Abbott, Boehringer Ingelheim, Eli Lilly, Merck Sharp \& Dohme, Novo Nordisk, Sanofi, Servier. Juan José Gagliardino, Hasan Ilkova, Ambady Ramachandran, Jean Claude Mbanya, Marina Shestakova and Pablo Aschner are members of the IDMPS Steering Committee and have received honoraria and traveling sponsorships in relation to the IDMPS.

Compliance with Ethics Guidelines. All patients gave written informed consent. Ethics approval was obtained from institutional review boards in each country and the study was 
conducted in accordance with the Declaration of Helsinki. Details of the informed consent form, along with information on national coordinators and participating physicians, can be found in Supplementary Materials.

Data Availability. Qualified researchers may request access to patient level data and related study documents including the clinical study report, study protocol with any amendments, blank case report form, statistical analysis plan, and dataset specifications. Patient level data will be anonymised and study documents will be redacted to protect the privacy of trial participants. Further details on Sanofi's data sharing criteria, eligible studies, and process for requesting access can be found at: https://www.clinicalstudydatarequest.com.

Open Access. This article is licensed under a Creative Commons Attribution-NonCommercial 4.0 International License, which permits any non-commercial use, sharing, adaptation, distribution and reproduction in any medium or format, as long as you give appropriate credit to the original author(s) and the source, provide a link to the Creative Commons licence, and indicate if changes were made. The images or other third party material in this article are included in the article's Creative Commons licence, unless indicated otherwise in a credit line to the material. If material is not included in the article's Creative Commons licence and your intended use is not permitted by statutory regulation or exceeds the permitted use, you will need to obtain permission directly from the copyright holder. To view a copy of this licence, visit http://creativecommons.org/licenses/by$\mathrm{nc} / 4.0 /$.

\section{REFERENCES}

1. International Diabetes Federation. IDF Diabetes Atlas, 9th ed. 2019. https://diabetesatlas.org/en/ resources/. Cited 6 Oct 2020.

2. McCarthy MI. Genomics, type 2 diabetes, and obesity. N Engl J Med. 2010;363(24):2339-50.
3. Luk AOY, et al. Diabetes-related complications and mortality in patients with young-onset latent autoimmune diabetes: a 14-year analysis of the prospective Hong Kong diabetes register. Diabetes Care. 2019;42(6):1042-50.

4. Ahlqvist E, et al. Novel subgroups of adult-onset diabetes and their association with outcomes: a data-driven cluster analysis of six variables. Lancet Diabetes Endocrinol. 2018;6(5):361-9.

5. Fonseca VA. Defining and characterizing the progression of type 2 diabetes. Diabetes Care. 2009;32(Suppl 2):S151-6.

6. American Diabetes Association (ADA). 6. Glycemic targets: standards of medical care in diabetes2020. Diabetes Care. 2020;43(Supplement 1): S66-76.

7. Aschner P, et al. Persistent poor glycaemic control in individuals with type 2 diabetes in developing countries: 12 years of real-world evidence of the International Diabetes Management Practices Study (IDMPS). Diabetologia. 2020;63(4):711-21.

8. Gagliardino JJ, et al. Type 2 diabetes: prescription patterns and treatment outcomes of IDMPS survey in Argentina. Diabetes Res Clin Pract. 2019;153: 86-92.

9. Khunti $\mathrm{K}$, et al. Clinical inertia with regard to intensifying therapy in people with type 2 diabetes treated with basal insulin. Diabetes Obes Metab. 2016;18(4):401-9.

10. Mauricio D, et al. Glycaemic control and hypoglycaemia burden in patients with type 2 diabetes initiating basal insulin in Europe and the USA. Diabetes Obes Metab. 2017;19(8):1155-64.

11. Russell-Jones D, Pouwer F, Khunti K. Identification of barriers to insulin therapy and approaches to overcoming them. Diabetes Obes Metab. 2018;20(3):488-96.

12. Donnelly LA, et al. Adherence to insulin and its association with glycaemic control in patients with type 2 diabetes. QJM. 2007;100(6):345-50.

13. Sarbacker GB, Urteaga EM. Adherence to insulin therapy. Diabetes Spectr. 2016;29(3):166-70.

14. Pastakia SD, et al. Diabetes in sub-Saharan Africafrom policy to practice to progress: targeting the existing gaps for future care for diabetes. Diabetes Metab Syndr Obes. 2017;10:247-63.

15. Chan JCN, et al. Multifaceted determinants for achieving glycemic control: the International Diabetes Management Practice Study (IDMPS). Diabetes Care. 2009;32(2):227-33. 
16. Ringborg A, et al. Resource use associated with type 2 diabetes in Asia, Latin America, the Middle East and Africa: results from the International Diabetes Management Practices Study (IDMPS). Int J Clin Pract. 2009;63(7):997-1007.

17. Gagliardino JJ, et al. Patients' education, and its impact on care outcomes, resource consumption and working conditions: data from the International Diabetes Management Practices Study (IDMPS). Diabetes Metab. 2012;38(2):128-34.

18. Casciano $\mathrm{R}$, et al. A quantitative assessment of patient barriers to insulin. Int $\mathrm{J}$ Clin Pract. 2011;65(4):408-14.

19. Gagliardino JJ, et al. Resource use associated with type 2 diabetes in Africa, the Middle East, South Asia, Eurasia and Turkey: results from the International Diabetes Management Practice Study (IDMPS). BMJ Open Diabetes Res Care. 2017;5(1): e000297.

20. Aschner, P, et al., High prevalence of depressive symptoms in patients with type 1 and type 2 diabetes in developing countries: results from the International Diabetes Management Practices Study. Manuscript submitted to diabetes care, 2021.

21. Cramer JA, et al. Medication compliance and persistence: terminology and definitions. Value Health. 2008;11(1):44-7.

22. Brown RJ, Rother KI. Effects of beta-cell rest on betacell function: a review of clinical and preclinical data. Pediatr Diabetes. 2008;9(3 Pt 2):14-22.

23. Skovlund SE, Peyrot M. The Diabetes Attitudes, Wishes, and Needs (DAWN) Program: a new approach to improving outcomes of diabetes care. Diabetes Spectr. 2005;18(3):136-42.

24. Perez-Nieves $M$, et al. Adherence to basal insulin therapy among people with type 2 diabetes: a retrospective cohort study of costs and patient outcomes. Diabetes Ther. 2018;9(3):1099-111.

25. Anderten H, Dippel F-W, Kostev K. Early discontinuation and related treatment costs after initiation of Basal insulin in type 2 diabetes patients: a German primary care database analysis. J Diabetes Sci Technol. 2015;9(3):644-50.

26. Ascher-Svanum $\mathrm{H}$, et al. Early discontinuation and restart of insulin in the treatment of type 2 diabetes mellitus. Diabetes Ther. 2014;5(1):225-42.

27. Del Degan S, et al. Risk factors for recurrent diabetic ketoacidosis in adults with type 1 diabetes. Can J Diabetes. 2019;43(7):472-6 ((e1)).
28. Genuth S, et al. Implications of the United kingdom prospective diabetes study. Diabetes Care. 2003;26(Suppl 1):S28-32.

29. King P, Peacock I, Donnelly R. The UK prospective diabetes study (UKPDS): clinical and therapeutic implications for type 2 diabetes. Br J Clin Pharmacol. 1999;48(5):643-8.

30. Polonsky WH, et al. Identifying solutions to psychological insulin resistance: an international study. J Diabetes Complicat. 2019;33(4):307-14.

31. McGill M, et al. The interdisciplinary team in type 2 diabetes management: challenges and best practice solutions from real-world scenarios. J Clin Transl Endocrinol. 2016;7:21-7.

32. Mbanya JC, et al. Self-monitoring of blood glucose (SMBG) and glycaemic control in Cameroon: results of the International Diabetes Management Practices Study (IDMPS). Diabetes Res Clin Pract. 2017;126: 198-201.

33. Alsayed K, Ghoraba M. Assessment of diabetic patients' adherence to insulin injections on basalbolus regimen in diabetic care center in Saudi Arabia 2018: Cross sectional survey. J Family Med Prim Care. 2019;8(6):1964-70.

34. Aminde LN, et al. Adherence to antidiabetic medication and factors associated with non-adherence among patients with type-2 diabetes mellitus in two regional hospitals in Cameroon. BMC Endocr Disord. $2019 ; 19(1): 35$.

35. Wu H, et al. Association between educational level and cardiovascular disease and all-cause mortality in patients with type 2 diabetes: a prospective study in the Joint Asia Diabetes Evaluation Program. Clinical Epidemiol. 2018;10:1561-71.

36. Saydah S, Lochner K. Socioeconomic status and risk of diabetes-related mortality in the U.S. Public health reports (Washington, D.C.: 1974). 2010;125(3):377-88.

37. Chan JCN, et al. Lancet commission on diabetes: using data to transform diabetes care and patient lives. Lancet. 2020;396(10267):2019-82.

38. Norris SL, et al. Self-management education for adults with type 2 diabetes: a meta-analysis of the effect on glycemic control. Diabetes Care. 2002;25(7):1159-71.

39. Lim LL, et al. Aspects of multicomponent integrated care promote sustained improvement in surrogate clinical outcomes: a systematic review and meta-analysis. Diabetes Care. 2018;41(6): 1312-20. 
40. Gagliardino JJ, et al. Clinical, metabolic and psychological outcomes and treatment costs of a prospective randomized trial based on different educational strategies to improve diabetes care (PRODIACOR). Diabet Med. 2013;30(9):1102-11.

41. Krass I, Schieback P, Dhippayom T. Adherence to diabetes medication: a systematic review. Diabet Med. 2015;32(6):725-37.

42. World Health Organization. WHO model list of essential medicines. 2017. https://apps.who.int/
iris/bitstream/handle/10665/273826/EML-20-eng. pdf?ua=1. cited 8 July 2019.

43. Baumgartner PC, et al. A systematic review of medication adherence thresholds dependent of clinical outcomes. Front Pharmacol. 2018;9:1290.

44. Brown MT, Bussell JK. Medication adherence: WHO cares? Mayo Clin Proc. 2011;86(4):304-14. 